\title{
A Geochemical Comparison of the Galápagos and Hawai'i Plumes
}

\author{
KAREN HARPP' AND DOMINIQUE WEIS²
}

Department of Geology, Colgate University, Hamilton, NY USA, kharpp@colgate.edu

Pacific Centre for Isotopic and Geochemical Research,

Department of Earth, Ocean, and Atmospheric Sciences, University of British Columbia, Vancouver, BC Canada, dweis@eoas.ubc.ca

New high-precision $\mathrm{Pb}, \mathrm{Sr}, \mathrm{Nd}$, and $\mathrm{Hf}$ isotopic analyses of $>80$ lavas from across the Galápagos Archipelago show that, like Hawai' $i$, the Galápagos is a bilaterally asymmetric plume with a NW-SE-trending compositional boundary. These two major plumes also share a common component in the lower average Pacific mantle and originate at the LLSVP-lower mantle interface. The southern parts of both plumes are sourced in the Pacific LLSVP, but differ compositionally from each other; in Galápagos, southernsourced lavas exhibit a HIMU mantle endmember contribution, whereas Loa trend lavas are dominated by EM1. Thus, the Pacific LLSVP must be compositionally heterogeneous and include a variety of different recycled materials. The distribution of isotopic ratios across the Galápagos and Hawai'i also confirms that bilaterally asymmetric plumes are strongly influenced by their tectonic settings, resulting in differences in geochemical and morphological characteristics of individual volcanoes. In Hawai' $i$, where the lithosphere is older and thicker than in Galápagos, volcanoes follow a systematic evolution process that terminates with highly-alkalic, rejuvenated volcanism. In the Galápagos, the thin lithosphere results in long-lived, widespread volcanism and inhibits Hawai'i-style rejuvenated-stage activity. Furthermore, the proximity of a mid-ocean ridge significantly affects the surficial expression of the bilaterally asymmetric plume. In the Galápagos, the adjacent spreading center generates upper mantle entrainment, overwhelming depleted material intrinsic to the plume and affecting volcanoes' magmatic architecture. Finally, the geometric relationship between plate motion and the deep LLSVP boundary strongly impacts the expression of deep mantle compositional structure at the surface. 